\title{
Potential Benefits from Innovations to Reduce Heat and Water Stress in Agriculture
}

\author{
Nathan P. Hendricks*
}

\begin{abstract}
A key challenge in determining the optimal research and development (R\&D) investment portfolio for adapting to climate change in agriculture is to understand the potential benefits from reducing alternative sources of climate damages. Existing econometric studies are not able to separately identify the impacts of heat and water stress because higher temperatures cause damages through both mechanisms. To resolve the identification problem, I introduce measures of water deficit and water surplus into a regression analysis that estimates the nonlinear impacts of heat and water stress on nonirrigated rental rates in the central United States. The results indicate rental rate losses of $33 \%$ ( $\$ 9.5$ billion annually) by mid-century due to climate change in scenario RCP 4.5. I find that $65 \%$ of the projected damages are due to heat stress, $32 \%$ due to increasing water deficit, and $3 \%$ due to increasing water surplus. However, the source of damages varies spatially.
\end{abstract}

JEL codes: Q54, Q55, Q16.

Keywords: Agriculture, Climate change, Adaptation, Ricardian analysis

Agriculture is heavily reliant on the climate and is thus vulnerable to climate change. Potential losses of agricultural production are especially concerning given the prospects of increasing global demand due to expected increases in global population and incomes. A large number of articles have examined the vulnerability of agriculture to climate change by evaluating the magnitude of damages (e.g., Adams et al. 1990; Schlenker, Hanemann and Fisher 2006; Schlenker and Roberts 2009; Deryng et al. 2014), the potential for adaptation through changes in existing production practices (e.g., Ortiz-Bobea and Just 2013; Huang, Wang and Wang 2015; Rosenzweig and Hillel 1998; Howden et al. 2007; Porter et al. 2014),

*Nathan Hendricks is at the Department of Agricultural Economics of Kansas State University (nph@ksu.edu). This material is based upon work supported by the National Science Foundation under Award No. EPS-0903806 and matching support from the State of Kansas through the Kansas Board of Regents. I thank Andrew Barkley, Jesse Tack, Ariel Ortiz-Bobea, Nicolas Quintana-Ashwell, Jeff Peterson, and seminar participants at Michigan State University, Iowa State University, the AERE annual meeting, and the AAEA annual meeting for helpful comments. I do not have any financial relationships that relate to this research. 
and the impact of adjustments in trade patterns (Reilly and Hohmann 1993; Rosenzweig and Parry 1994; Costinot, Donaldson and Smith 2016).

Another method to mitigate damages is to invest in research and development (R\&D) to induce innovations that mitigate the negative impacts of climate stress (Lobell et al. 2008; Olmstead and Rhode 2011). Estimates of potential benefits and costs of R\&D investments are especially important in agriculture, where public spending represents nearly half of all R\&D expenditures in OECD countries and roughly 64\% of R\&D expenditures globally (Pray and Fuglie 2015). A key question that arises in determining an optimal R\&D investment portfolio is to estimate the potential benefits from mitigating alternative sources of climate damages, which requires an estimate of the mechanisms that cause climate damages.

Previous literature shows a robust negative effect of extreme heat on agriculture by regressing land values or crop yield on nonlinear functions of temperature and precipitation (e.g., Schlenker, Hanemann and Fisher 2006; Schlenker and Roberts 2009; Lobell et al. 2011; Tack, Barkley and Nalley 2015), but confounds the impacts of higher temperatures through heat and water stress. Higher temperatures cause "heat stress" damages through faster crop development (which reduces crop yield), negative impacts during the reproductive stage, oxidative stress, and damages to enzymes and tissue (Hatfield et al. 2011; Schauberger et al. 2017). However, higher temperatures also cause water stress by increasing the atmospheric water demand (i.e., the evapotranspiration demand for crops). ${ }^{1}$ My research seeks to separately identify these two mechanisms through which temperature affects crops in order to assess whether adaptation efforts should focus primarily on reducing heat or water stress.

To resolve the identification problem, I introduce measures of water deficit and water surplus into my regression analysis in place of precipitation. Water deficit is defined as the evapotranspiration (ET) demand not met by available water (Stephenson 1990), where the ET demand is modeled with a "reference" crop. Water surplus is the amount of precipitation in excess of ET demand. Reference ET converts temperature into units of atmospheric water demand, which is then incorporated with precipitation into a daily water balance model to calculate water deficit and surplus (Thornthwaite 1948; Stephenson 1990). Off-season precipitation, timing, and daily intensity of precipitation events all affect measures of water deficit and water surplus through storage of water in the soil. Furthermore, the water balance model incorporates spatial variability in soil water holding capacity.

I find that $65 \%$ of damages from projected climate change are due to heat stress, $32 \%$ due to water deficit, and $3 \%$ due to water surplus. Heat stress is especially important for climate change adaptation due to the large projected increases in heat stress due to temperature

\footnotetext{
${ }^{1}$ Schauberger et al. (2017) refer to "heat stress" as the direct effect of temperature increases and "water stress" as the indirect effect.
} 
increases. Overall, I find that projected damages by mid-century are expected to be $33 \%$ of current agricultural rents. There is a large amount of uncertainty in these damages, mostly due to varying projections across climate models. The $90 \%$ confidence interval due to uncertainty in regression coefficients alone is $[-38.5 \%,-27.1 \%]$ and uncertainty due to different projections across climate models is $[-55.2 \%, 11.7 \%]$. However, rents are expected to decline for all but one climate model and thus provide a strong rationale for increasing R\&D expenditures to offset these damages in the future. Decomposing the damages by mechanism suggests that additional effort should particularly be placed on reducing heat stress. The simulations also indicate that the optimal allocation of R\&D effort between heat and water stress varies across space.

I also consider a specification similar to previous literature (i.e., the traditional model) that uses precipitation in place of water deficit and water surplus. The traditional model indicates a similar magnitude of overall damages and indicates that nearly all of the projected damages are due to temperature increases. However, the traditional model is not able of identify how much of the damages occur through water stress versus heat stress since a temperature increase causes damages through both mechanisms. Therefore, while the traditional model predicts overall damages well, it does not inform strategies for adaptation.

My work is related to previous literature that has informed priorities for R\&D investments. Lobell et al. (2008) focus on prioritizing R\&D investments by crops and regions. Singh et al. (2014) use a crop simulation model to analyze the yield benefits from drought or heat tolerant traits in sorghum. Lobell et al. (2013) and Schauberger et al. (2017) use crop simulation models to identify the impact of temperature increases through heat versus water stress, but my research is the first to use econometric methods to identify economic benefits from reducing each type of stress.

I adopt the approach of many recent economic studies that estimate the impact of variations in current climate - or weather - on economic outcomes in order to inform future potential impacts (Dell, Jones and Olken 2014). In particular, I estimate a cross-section regression of nonirrigated cash rental rates in the central United States on nonlinear functions of average weather measures while controlling for soil characteristics. My approach follows the Ricardian - or hedonic - model pioneered by Mendelsohn, Nordhaus and Shaw (1994) and applied in many different regions of the world (e.g., Polsky 2004; Schlenker, Hanemann and Fisher 2006; Seo et al. 2009; Massetti and Mendelsohn 2011; Fezzi and Bateman 2015; Dall'erba and Domínguez 2016). ${ }^{2}$

Examining the effect of climate on agricultural rents has several advantages over models that examine the effect of weather variability on crop yields. First, examining the impact on

\footnotetext{
${ }^{2}$ For a comprehensive review of the literature see Mendelsohn and Dinar (2009).
} 
rents accounts for adaptation through currently available production practices since farmers in each county have an incentive to adopt the optimal cropping pattern, cropping frequency, and production practices given their climate. Second, I exploit variation in average water deficit across counties which has minimal measurement error compared to the deviations from normal exploited by panel models with fixed effects (Auffhammer et al. 2013). Thus, previous statistical studies may understate the importance of water stress due to attenuation bias from measurement error but I am not able to determine the magnitude of this bias in panel studies. Finally, my model provides direct estimates of economic impacts that are critical for policy analysis.

The primary critique of the Ricardian approach is that omitted variables that affect land values may also be correlated with climate variables. I address concerns about omitted variables by using nonirrigated rental rates rather than land values, restricting the estimation to a region with similar crop production practices, carefully constructing detailed soils data, including state fixed effects, and conducting a robustness check using the post-double-selection method to select controls proposed by Belloni, Chernozhukov and Hansen (2014). Another critique of Ricardian models is that the estimates may reflect adaptation that occurs over several decades or even centuries and may not be a relevant time scale for adaptation to climate change (Dell, Jones and Olken 2014). Furthermore, Ricardian estimates do not reflect the cost of adaptation (Quiggin and Horowitz 1999). These concerns are likely small in my sample where the majority of nonirrigated cropland is planted to a few field crops with relatively similar production practices.

\section{Conceptual Model}

The Ricardian rent represents the value of land in its most valuable use net of input costs. Assuming a competitive market, the cash rental rate for land equals the Ricardian rent. One can visualize rent as a function of a climate characteristic as the envelope of rent functions specific to each land use since farmers optimally reallocate land to different cropping patterns for different climates (see Mendelsohn, Nordhaus and Shaw 1994). Therefore, economic theory does not provide guidance on the functional form for the rent function. It is also worth noting that a nonlinear rent function is consistent with linear crop-specific yield responses to a climate variable, as suggested by the agronomic literature with respect to water availability (e.g., Fereres and Soriano 2007; Lobell et al. 2013). The rent function also reflects adjustments of fertilizer intensity, planting density, and crop varieties depending on the climate and soil. 
I estimate the rent function econometrically and then use it to estimate the potential benefits from innovations that would reduce the negative impacts of heat or water stress. To simplify notation, assume that Ricardian rent is a function of three climate characteristics: water deficit (deficit), water surplus (surplus), and heat stress (heat). Consider the benefits from an innovation that reduces damages from water deficit-assuming that the new technology can be represented as a substitute for reduced water deficit. For example, the benefit of a new drought tolerant crop variety could be represented as a decrease in the "effective" water deficit. The economic benefits from the innovation are calculated using the rent function as follows

$$
\Delta_{\text {deficit }}=R\left(\text { deficit }_{1}, \text { surplus }_{0}, \text { heat }_{0}\right)-R\left(\text { deficit }_{0}, \text { surplus }_{0}, \text { heat }_{0}\right),
$$

where $R(\cdot)$ denotes the Ricardian rent function, the subscript 0 denotes the original level of the climate variables, and the subscript 1 denotes the "effective" new water deficit after the innovation.

The rent function can also be used to estimate the potential benefits from innovations to offset the impacts of climate change. Note that the benefits from innovations that offset climate damages are simply the opposite of the damages due to climate change. To estimate the overall damages from climate change, I calculate the predicted rent with projected values of the climate and subtract the predicted rent with historical climate. I also isolate the damages from climate change due to an increase in water deficit using the same formula in equation (1) but where the subscript 1 denotes the projected water deficit due to climate change, and similarly for the other climate variables.

To be clear about terminology, I use the term "adaptation" to refer to any action that offsets the impact from climate change (see Lobell 2014). Adaptation can occur through changes in existing production practices or the development of new technologies (i.e., innovations). The rent function that I estimate reflects optimal adaptation through changes in practices currently available and I use this rent function to estimate the benefits from innovations to adapt to climate change. Damages from climate change could also be partly mitigated by changes in crop prices inducing a supply response and causing changes in international trade patterns. The estimates in this paper do not account for any adjustments due to changes in prices.

\section{Data Description}

The objective of my econometric model is to estimate the Ricardian rent function. As I describe in detail in the next section, I regress nonirrigated rental rates on flexible functional 
forms of climate characteristics while controlling for soil characteristics and state fixed effects. Nonirrigated cash rents in 2013 at the county-level are obtained from the National Agricultural Statistics Service (NASS). NASS has reported cash rental rates annually since 2008, though rental rates are not reported for every county depending on the response rate. I estimate the model using a cross-section of data in 2013. I restrict the analysis to counties with a majority of their land area in one of six Land Resource Regions defined by NRCS - central feed grains, lake states (excluding counties in New York), Mississippi Delta, central great plains, western great plains, and northern great plains (see figure A1 in the supplementary appendix).

\subsection{Historical Climate}

I construct four variables to describe the climate in each county: water deficit, water surplus, growing degree days (GDDs), and extreme degree days (EDDs). Water deficit is defined as the "evaporative demand not met by available water, a measure of how much more water could have been evaporated or transpired from a site covered by a standard crop, had the water been available" (Stephenson 1990, p. 651). Water surplus is the amount of precipitation in excess of evapotranspiration (ET) demand by a standard (i.e., reference) crop. GDDs measure the exposure to heat within a range of temperatures considered beneficial to crop growth and EDDs measure the exposure to heat from temperatures not beneficial to crop growth (Schlenker, Hanemann and Fisher 2006; Lobell et al. 2011).

I calculate the cumulative measure for each of these variables within the growing season (April 1-September 30) for each year then calculate the 30-year average (1983-2012) in order to describe the climate of each county. One potential concern is that the growing season differs for winter wheat, which is an important crop in some regions in my data. However, the econometric model examines the impact of climate on cash rent and is not crop-specific. Climate during times outside the growing-season for wheat are still relevant for the rental rate on land producing wheat by influencing the crop choice. For example, extreme heat in late summer could induce some farmers to plant winter wheat when they could have produced a higher value crop instead. Another potential concern is that the use of aggregate data could introduce bias (Fezzi and Bateman 2015), but there is likely little bias in my analysis because there is minimal within-county variation in the average climate (section A2 in the supplementary appendix).

These four variables are constructed using daily precipitation, maximum temperature, and minimum temperature from $\mathrm{PRISM}^{3}$ and the water holding capacity within the root zone from the gSSURGO (gridded Soil Survey Geographic) database created by NRCS (Natural

\footnotetext{
${ }^{3}$ PRISM Climate Group, Oregon State University, http://prism. oregonstate.edu, created 4 Feb 2004.
} 
Resources Conservation Service). PRISM interpolates data from a large number of weather station networks to a $4 \mathrm{~km}$ grid covering the contiguous United States. I used the meta-file provided by Wolfram Schlenker and Michael Roberts in order to link each grid cell in PRISM to a county. ${ }^{4}$

Water deficit and water surplus are measured using a water balance model (Thornthwaite 1948; Stephenson 1990). The amount of water stored in the soil (i.e., soil moisture) in a day is the soil moisture from the previous day plus precipitation minus reference ET demand. The soil moisture is constrained to be non-negative and less than or equal to the average water holding capacity of the soils on cropland within the county. Actual ET-according to the usage of the term by Stephenson (1990) - is the ET demand by the reference crop given the water available. ${ }^{5}$ When available soil moisture and precipitation exceed reference ET demand, then actual ET is equal to reference ET. When available soil moisture and precipitation are less than reference ET demand, then actual ET is equal to available soil moisture plus precipitation. Water deficit is the difference between reference ET and actual ET. Water surplus is the water available in excess of the water holding capacity of the soil. ${ }^{6}$

I initialize the water balance model by assuming the soil moisture on January 1, 1981 was half of the soil water holding capacity - daily PRISM data are available beginning in 1981. I run the daily water balance model through 2012 and discard the first two years of data to obtain a 30-year average. The average water deficit and surplus are very similar if I initialize soil moisture at zero instead of half of the maximum water holding capacity, so the initialization is an innocuous assumption. ${ }^{7}$ Note that water deficit and water surplus within the growing season - my explanatory variables - account for precipitation during the non-growing season through soil moisture. That is, a county with more precipitation during winter months will have less water deficit during the growing season because that county has more water stored in the soil at the beginning of the growing season.

Reference ET is a measure of the evaporative demand independent of crop characteristics and soil factors within a particular county. Reference ET is defined as the ET of a wellwatered, actively growing grass (Allen et al. 1998). Using an alternative measure of ET based on the crops that are actually planted in each county creates an endogeneity problem-ET

\footnotetext{
${ }^{4}$ To be clear, the daily precipitation and temperature data that I use are directly from PRISM. I use a meta-file posted online by Schlenker and Roberts to link each grid cell to a county (available at http://www.wolfram-schlenker.com/).

${ }^{5}$ Other authors use the term "actual ET" to mean the ET demand of the observed land use.

${ }^{6}$ Water deficit and water surplus cannot be combined into a single variable since a county can have both a positive deficit and surplus over a growing season.

${ }^{7}$ Initializing the model with zero soil moisture increases average water deficit by $0.08 \%$ for one county and has no effect on water deficit in all other counties. Water surplus does not change for more than $99 \%$ of counties in the sample with the alternative initialization. The initialization makes little difference because I discard the first two years of data before calculating average values.
} 
is smaller in counties with less acreage in water-intensive crops, which are associated with low rental rates. I calculate reference ET using the reduced-set Penman-Monteith method that requires only maximum and minimum temperature data. The full Penman-Monteith equation requires additional data on solar radiation, vapor pressure, and wind speed (Allen et al. 1998). In the absence of these additional measures, I follow the method described by Allen et al. (1998) to approximate these measures with temperature data (section A3 in the supplementary appendix provides a complete description). I use water deficit with reference ET instead of vapor pressure deficit, Palmer Drought Severity Index, observed soil moisture, or ET of planted crops because temperature is translated into units of water demand and using reference ET avoids endogeneity concerns across counties with different land uses as discussed in more detail in section A4 of the supplementary appendix.

Temperature plays an important role in the calculation of ET, and thus impacts water deficit and surplus. For illustrative purposes, I increased the minimum and maximum temperatures in each day by $2^{\circ} \mathrm{C}$ for every county in my dataset. On average, the $2^{\circ} \mathrm{C}$ change in temperature increases ET by 1.7 inches (5.3\%), increases water deficit by 1.5 inches (17.9\%), and decreases water surplus by 0.2 inches $(16.8 \%)$.

I calculate GDDs as the degree days between $10^{\circ} \mathrm{C}$ and $30^{\circ} \mathrm{C}$ and EDDs as the degree days greater than $34^{\circ} \mathrm{C}$ within the growing season using a sinusoidal interpolation of temperature (Snyder 1985). I scale growing degree days to hundreds of growing degree days but do not scale extreme degree days. Some articles find that temperatures greater than $30^{\circ} \mathrm{C}$ are harmful to crop production, but Lobell et al. (2013) and Schauberger et al. (2017) find that this effect is partly due to greater water stress at higher temperatures, which I account for by including ET in the water balance model. Ritchie and Nesmith (1991) suggest that temperatures greater than $34^{\circ} \mathrm{C}$ are harmful for crop production and Deryng et al. (2014) suggest that temperatures greater than $32^{\circ} \mathrm{C}$ and $35^{\circ} \mathrm{C}$ are harmful for corn and soybeans, respectively. I use cross-validation to compare predictive ability of the alternative thresholds of $30,31,32,33,34,35$, or $36^{\circ} \mathrm{C}$ and found that $34^{\circ} \mathrm{C}$ provided the best out-of-sample prediction ability.

\subsection{Soils}

I collect detailed soil characteristics from the gSSURGO database created by NRCS. I aggregate soil characteristics for each county using only areas classified by remote sensing as cropland from the NLCD (National Land Cover Database). One of the most important soil characteristics is its water holding capacity. The water holding capacity plays an important role in the water balance model, so I do not include it as a separate control. 
My preferred regression specification includes the following soil characteristics as controls: soil organic carbon, bulk density, electrical conductivity, proportion of cropland with a $\mathrm{pH}$ less than 6, proportion of cropland with a $\mathrm{pH}$ greater than 7.5, and the log of slope. These soil characteristics were chosen to represent indicators of the five functions of soil: sustaining biological diversity and productivity (D); regulating water (W); filtering, buffering, and degrading organic and inorganic materials $(\mathrm{F})$, storing and cycling nutrients and carbon $(\mathrm{N})$, and providing physical stability (S) (NRCS, USDA 2015). I also selected soil characteristics that cannot be highly altered by management practices.

Soil organic carbon (SOC) affects plant growth by providing a source of energy for soil microorganisms and impacting nutrient availability through mineralization (D and N). SOC is highly correlated with organic matter. Bulk density indicates the soil compaction, which impacts the movement of water and air through soil and root growth (W and S). A larger bulk density indicates poorer soils. Electrical conductivity (EC) is an indicator of salinity and the amount of nutrients available ( $\mathrm{N}$ and $\mathrm{D})$. Larger values of EC indicate more salinity and poorer soils. Soil pH indicates the degree of acidity or alkalinity which impacts organic matter mineralization and nitrification ( $\mathrm{F}$ and $\mathrm{N}$ ). Yields for most crops decrease if the $\mathrm{pH}$ is less than 6 or greater than 7.5 (NRCS, USDA 2015). While the slope of the land is not an indicator of soil quality, it clearly has important impacts on crop productivity. I use the log of slope because the distribution of slope across counties is skewed, with a few counties highly sloped. In contrast to many previous studies, I do not include the land capability classification as a control because the classification depends in part on climatic conditions (Klingebiel and Montgomery 1961).

\subsection{Climate Projections}

I use the most recent projections from climate models to model the change in each climate variable by mid-century (2036-2065). I use the Downscaled CMIP5 Daily Climate Projections to provide fine resolution projections for the contiguous United States (Reclamation 2013). These downscaled climate projections are derived from the CMIP5 multi-model ensemble dataset used to inform the IPCC (Intergovernmental Panel on Climate Change) Fifth Assessment. ${ }^{8}$ The list of 18 climate models and institutions included in my ensemble are listed in table A2 in the supplementary appendix. I report estimated damages using an ensemble average - averaging the predicted change in each climate variable across all models - and report the variability in estimated damages across climate models.

\footnotetext{
${ }^{8}$ County-level aggregates were obtained through the US Geological Survey Geo Data Portal at http://cida.usgs.gov/gdp/.
} 
The water balance model is initialized on January 1, 2034 assuming initial soil moisture is half of the maximum water holding capacity. The first two years are discarded and I calculate the average for each climate variable over the 30-year period 2036-2065. I calculate the change in each climate variable compared to the historical simulation for each model since the historical climate simulated by each model may be different from the PRISM data.

Auffhammer et al. (2013) identify two main challenges with using projections from climate models in simulations. First, they note that different climate models can indicate different projections, so reporting results using a single climate model can be misleading. I report simulations with an ensemble average and report the variability across climate models. Second, Auffhammer et al. (2013) note that there can be aggregation bias from using climate models since their output has a resolution much coarser than the size of a U.S. county. I address this issue by using spatially downscaled climate projections and by using the change in each climate variable relative to the historical simulation of each model.

The IPCC Fifth Assessment defines future scenarios of radiative forcing as Representative Concentration Pathways (RCPs). I consider scenario RCP 4.5 in my simulations. RCP 4.5 is a stabilization pathway where radiative forcing is stabilized by 2100 with emissions decreasing in the last half of the 21st century (Moss et al. 2010).

\section{Econometric Model}

I estimate the Ricardian rent function with the regression

$$
\ln \left(R_{i}\right)=f_{d}\left(\text { deficit }_{i}\right)+f_{s}\left(\text { surplus }_{i}\right)+f_{G}\left(G D D_{i}\right)+f_{E}\left(E D D_{i}\right)+\boldsymbol{\theta}^{\prime} \mathbf{X}_{i}+\alpha_{j}+\varepsilon_{i}
$$

where $\ln \left(R_{i}\right)$ is the natural logarithm of the nonirrigated cash rental rate for county $i$; deficit $_{i}$ is average water deficit; surplus $_{i}$ is average water surplus; $G D D_{i}$ is average growing degrees between $10^{\circ} \mathrm{C}$ and $30^{\circ} \mathrm{C} ; E D D_{i}$ is extreme degree days greater than $34^{\circ} \mathrm{C} ; f_{m}(\cdot)$ is a flexible functional form for the respective variable $m ; \mathbf{X}_{i}$ is a vector of soil characteristics described in the data section; and $\alpha_{j}$ are state fixed effects. The errors $\left(\varepsilon_{i}\right)$ are assumed to be heteroskedastic and spatially autocorrelated. I use the log rental rate as the dependent variable rather than the level of the rental rate because rental rates are skewed - a small number of counties have high rental rates. Regressions are weighted by the acreage of nonirrigated cropland in the county obtained from the 2012 Census of Agriculture. 
Given the lack of guidance from theory, I estimate flexible functional forms for the rent function. ${ }^{9}$ I specify the $f_{m}(\cdot)$ 's as restricted cubic splines and choose the optimal number of knots using cross-validation. I consider the possibility of 3 to 6 knots for each function as well as a linear function. Cross-validation is conducted using groups of states as the folds so that each fold has a similar number of observations. ${ }^{10}$ That is, I estimate the regression model using data from $S-1$ state groups and estimate the root mean squared error for the prediction on the omitted state group, where $S$ denotes the total number of state groups in my data. Then I repeat this process by leaving out each state group and averaging the prediction error across state groups. This process is repeated for each possible combination of spline knots and I choose the optimal number of knots for each function as the combination that minimizes the average prediction error. Cross-validation selects a linear function for water deficit and water surplus, and 3 spline knots for GDDs and EDDs.

The model specification in equation (2) assumes that cash rent is determined by the net returns from crop production and that net returns are represented by a function of climate and soil characteristics. An advantage of using rental rates as the dependent variable is that rent only depends on short-run returns from agricultural production. Land values used in previous studies (e.g., Schlenker, Hanemann and Fisher 2006; Fezzi and Bateman 2015) depend on the future stream of expected benefits from agricultural and non-agricultural uses and therefore depend on a large number of factors other than agricultural returns such as real interest rates, real returns on alternative uses of capital, potential for urban development, recreational amenities, and mineral rights (Featherstone and Baker 1987; Just and Miranowski 1993; Plantinga and Miller 2001; Borchers, Ifft and Kuethe 2014). ${ }^{11}$ Since I use rental rates, I omit socio-economic variables related to non-agricultural uses of land.

Some previous studies include agricultural subsidies as a right-hand side variable (Polsky 2004; Massetti and Mendelsohn 2011; Dall'erba and Domínguez 2016). However, subsidies may be endogenous since subsidy rates tend to be larger on more productive land (Kirwan 2009). Polsky (2004) and Massetti and Mendelsohn (2011) assume agricultural subsidies are exogenous while Dall'erba and Domínguez (2016) implements a two-stage-least squares approach. Ethanol plant locations may also affect rents through increases in local grain

\footnotetext{
${ }^{9}$ Fezzi and Bateman (2015) also use restricted cubic splines, but I use an alternative method of selecting the optimal number of spline knots. Most previous Ricardian models impose quadratic functional forms (e.g., Mendelsohn, Nordhaus and Shaw 1994; Seo et al. 2009).

${ }^{10}$ The following groups of states were created: Colorado, Wyoming, and Montana; New Mexico and Texas; Missouri and Tennessee; Arkansas, Mississippi, and Louisiana; Minnesota and Wisconsin. All remaining states were not combined with other states.

${ }^{11}$ Of course, my estimates are closely related to previous studies that use land values assuming that land values represent the net present value of the stream of expected rents and other potential benefits from the land.
} 
prices. But ethanol plant locations are also likely endogenous - ethanol plants may have chosen to locate in areas with greater land productivity (Towe and Tra 2013). I omit subsidies and ethanol production due to these endogeneity concerns, but including them and urban influence variables has minimal impact on my results (see table A3 in the supplementary appendix). ${ }^{12}$

A test of OLS residuals indicates significant spatial dependence using an inverse-distance weighting matrix (Moran's I test with null hypothesis of spatial independence: p-value<0.01). And a test indicates significant heteroskedasticity (Breusch-Pagan test with null hypothesis homoskedasticity: p-value<0.01). I account for spatial dependence and heteroskedasticity by clustering standard errors by the groups of states used for cross-validation. ${ }^{13}$ Bester, Conley and Hansen (2011) propose clustering by large spatial blocks as a simple method to account for spatial correlation, relying on the assumption that relatively few observations are near borders that may be correlated with observations in other clusters. Bester, Conley and Hansen (2011) show that clustering provides valid inference as long as the clusterlevel averages are approximately independent, even though observations near the borders in different clusters are correlated. This assumption is supported by failing to reject the null hypothesis of spatial independence of cluster-average OLS residuals using an inverse-distance weighting matrix (Moran's I: p-value=0.22). Fisher et al. (2012) and Burke and Emerick (2016) also cluster by state using similar data. Table A4 in the supplementary appendix shows regression results with a spatial error model and heteroskedastic disturbances using an inverse-distance weighting matrix (Kelejian and Prucha 2010). Standard errors are larger in the case of cluster standard errors, so my estimates are more conservative than the spatial error model.

County fixed effects cannot be used in my study to control for unobserved heterogeneity of counties because there is minimal variation in rental rates from year to year due to weather shocks. In contrast, studies that examine the effect of weather shocks on crop yields can use fixed effects to isolate the effect of random weather shocks (e.g., Schlenker and Roberts 2009; Welch et al. 2010; Chen, Chen and Xu 2016). A key advantage of the fixed effects approach is that deviations of weather from normal conditions are exogenous - that is, uncorrelated with omitted variables. One disadvantages of exploiting weather shocks is that the approach does not account for potential adaptation. Another disadvantage is that models with fixed effects have greater bias due to measurement error of weather characteristics (see section

\footnotetext{
${ }^{12}$ Data on agricultural subsidies are the direct payments per cropland acre obtained from the Farm Program Atlas by USDA, ERS. I include the log of subsidies as a control. Data on ethanol production in each county are from Woodard (2016). Dummy variables for urban influence are from the 2013 Urban Influence Codes created by USDA, ERS.

${ }^{13}$ See footnote 10.
} 
A6 in the supplementary appendix for a detailed explanation). Auffhammer et al. (2013) compare alternative global gridded weather datasets and find a substantial agreement about average temperature and precipitation. However, there is less agreement about deviations from normal, especially for precipitation.

Burke and Emerick (2016) take an alternative approach where they use long differences to estimate the impact of historical changes in climate on agriculture over a 30-year period. Burke and Emerick (2016) argue that their approach should account for adaptation while still controlling for unobserved heterogeneity of counties. Disadvantages of the long difference approach are that it exploits a relatively small amount of variation in climate and the differences may not reflect long-run trends - or at least farmer perceived trends - in climate.

I make several efforts to reduce the potential omitted variable bias in the Ricardian approach. First, examining the impact on nonirrigated rental rates rather than land values reduces concerns about omitted variable bias. As mentioned earlier, several factor affect land values that do not affect rental rates and these alternative factors bias Ricardian estimates using land values if they are omitted and correlated with climate. For example, urban development tends to decrease moving from the eastern United States towards the Plains states and precipitation also tends to decrease. Warmer states may also have greater development potential and thus bias the effect of temperature. In addition, land values from the U.S. Census of Agriculture reflect the average of nonirrigated cropland, irrigated cropland, and pasture values. Schlenker, Hanemann and Fisher (2005) show that failing to account for irrigation in the model severely biases the estimates. Schlenker, Hanemann and Fisher (2006) attempt to alleviate the concern with irrigation by restricting the sample to counties east of the 100th meridian, but a majority of land is irrigated in the Mississippi Delta region (see figure A2 in the supplementary appendix). In contrast, my dependent variable does not reflect values from non-agricultural uses of the land or irrigated values.

To further reduce concerns about omitted variables, I include state fixed effects in my regression and restrict the analysis to counties with a majority of their land area in one of six Land Resource Regions. For studies that cover the entire United States, it is arguably difficult to imagine a set of variables that explain the difference between agricultural values in Mediterranean versus continental climates. The Great Plains, Corn Belt, and Mississippi Delta regions considered in my analysis are relatively homogeneous in that crop production is primarily comprised of grain and oilseed production.

I also check the robustness of my results using the post-double-selection method to select controls proposed by Belloni, Chernozhukov and Hansen (2014) in order to alleviate concerns that my estimates could be biased if I have chosen the wrong set of soil variables as controls. The procedure to select controls is as follows. In step 1, LASSO (Least Absolute Shrinkage 
and Selection Operator) selects variables that predict each of the variables constructed from the climate variables. ${ }^{14}$ In step 2, LASSO selects variables that predict the log of cash rent where climate variables are not included as potential regressors. In step 3, I estimate equation 2 using the union of selected soils controls from steps 1 and 2 as my $\mathbf{X}_{i}$. I consider 87 potential soils controls that include additional soil characteristics and nonlinear transformations of all the soil characteristics. More details on the post-double-selection method are provided in section A8 of the supplementary appendix.

\section{Data Exploration}

Table 1 provides summary statistics of the variables used in the econometric analysis. Figure 1 shows a map of nonirrigated cash rental rates in 2013 (color figures are available in the online version of this article). Rental rates are largest in the central Corn Belt and decline substantially moving west into the more arid Great Plains. There are some counties with missing data in 2013. These are counties where NASS did not have a large enough survey response rate to report an average rental rate.

Figure 2 shows maps of the four climate variables derived from PRISM data. Water deficit varies primarily along an east-west gradient, with much drier conditions in the west. The spatial distribution of water deficit is obviously highly related to precipitation, but there are some key differences due to the water holding capacity of the soil and ET demand. For example, southeast Kansas has greater growing-season precipitation than most of Iowa and Illinois, but the soil in southeast Kansas has a much smaller water holding capacity so the water deficit is the same or greater than Iowa and Illinois (see figures A3 and A4 in the supplementary appendix). Water surplus is greatest in the southeast.

Obviously precipitation and water deficit are highly correlated-but not perfectlyindicating that water deficit represents a distinct feature of the climate. The correlation coefficient between growing-season precipitation and water deficit is -0.89 and the correlation between precipitation and water surplus is 0.72 . Water deficit and surplus are also not perfectly negatively correlated, with a correlation coefficient of -0.63 . The correlation coefficient between EDDs and water deficit is 0.61 , so the regression analysis can separately estimate the impact of the two variables since they are not perfectly correlated. Reference ET - used to calculate water deficit - is also a distinct measure from GDDs (correlation coefficient $=0.71$ ) and EDDs (correlation coefficient=0.82).

\footnotetext{
${ }^{14}$ I use LASSO to select soil controls that predict 6 different variables that are constructed as transformations of my climate variables since a restricted cubic spline with $k$ knots is estimated by constructing $k-1$ variables.
} 
GDDs and EDDs vary along a north-south gradient (figure 2). The southern Great Plains have greater exposure to EDDs than the southern Mississippi Delta region even though GDDs are large in the southern Mississippi Delta region.

The ensemble average climate projection indicates that water deficit is expected to increase by 2.4 inches on average by mid-century (2036-2065) under scenario RCP 4.5. Water surplus is only projected to increase by 0.1 inches. GDDs are expected to increase by 3.2 hundred degree days. EDDs are expected to increase by 19.5 degree days on average compared to a mean of only 7.4 degree days in historical data. The largest increase in water deficit is expected to occur in the Plains and the largest increase in EDDs is expected in the South. The variation in projections across climate models and across space are shown in figures A5 and A6 of the supplementary appendix.

\section{$5 \quad$ Results}

\subsection{Estimates of the Rent Function}

Coefficients related to the restricted cubic splines are difficult to interpret, so I calculate the predicted value from equation (2) across the range of the variable observed in my data and set all other variables equal to median values. ${ }^{15}$ I then plot the predicted rental rate-rather than the predicted log rental rate-in figure $3 .^{16}$

Cross-validation selects a linear relationship between water deficit and log rent, which implies a convex function for the rental rate. The coefficient on water deficit indicates that a 1 inch increase in water deficit results in a $5.8 \%$ decrease in cash rent (table 2). Increasing water deficit from 5 to 10 to 15 inches decreases the rental rate from $\$ 236$ /acre to $\$ 177$ /acre to $\$ 132$ /acre with other variables held constant at median values (figure 3 ). Cross-validation also selects a linear relationship between water surplus and log rent. A 1 inch increase in water surplus decreases cash rent by $16.8 \%$. However, the magnitude of water surplus is much smaller than for water deficit, so the range in water deficit has a larger impact on rent than the range in water surplus (figure 3). Most studies assume a quadratic functional form for precipitation, where precipitation is assumed beneficial up to some point and then begins to have negative impacts. The rent functions in figure 3 reflect this same general relationship, but in a more realistic manner.

Rents increase rapidly as GDDs increase up to about 17 hundred degree days, reach a peak at about 20 hundred degree days, and then decrease slightly for additional GDDs

\footnotetext{
${ }^{15}$ The state fixed effect for Nebraska is set equal to 1 since Nebraska has an average rent similar to the overall average for the sample.

${ }^{16}$ In order to predict the rental rate, I calculate $\exp \left(\hat{y}+\hat{\sigma}^{2} / 2\right)$, where $\hat{y}$ is the predicted log rental rate and $\hat{\sigma}$ is the root-mean-squared-error.
} 
(figure 3). Rents increase with greater GDDs because farmers can grow higher valued crops, increase cropping frequency, or grow higher yielding crop varieties that require a longer growing season. It is also important to recognize that there is less confidence in the estimated relationship after GDDs increase beyond 20 hundred degree days. The predicted function for GDDs in figure 3 exceeds the observed data when GDDs are greater than 20 hundred degree days because I set all other variables - including EDDs - equal to their median values. Most of the counties with GDDs greater than 20 hundred degree days have large EDDs that lead to lower observed rental rates.

Rents are highly sensitive to increased exposure to temperatures that exceed $34^{\circ} \mathrm{C}$ (figure 3). Increasing EDDs from 0.1 to 5 to 10 decreases the rent from $\$ 340$ /acre to $\$ 152$ /acre to $\$ 94 /$ acre. Accumulating EDDs beyond 10 has a much smaller effect on rents, although rents are already mostly diminished. The estimated function for EDDs is slightly increasing when EDDs exceed 25, but the uncertainty in the predicted value increases for large EDDs.

I simulate the impact of a uniform $2^{\circ} \mathrm{C}$ increase in temperature to understand the impact of a temperature increase through heat and water stress while holding constant precipitation. Allowing the increase in temperature to only impact GDDs and EDDs results in a $8.5 \%$ decrease in rents and allowing the temperature increase to only impact water deficit results in a $8.9 \%$ decrease in rents. ${ }^{17}$ Therefore, more than half of the damages from an increase in temperature are due to water stress.

Table 2 shows regression coefficients, number of observations, and the $R^{2}$. The model explains $92.6 \%$ of the variation in the data. For soil characteristics, only the coefficients on $\mathrm{pH}$ less than 6 and the $\log$ of slope are statistically significant. As expected, low $\mathrm{pH}$ and a large slope decrease rent. The coefficients on SOC and bulk density also have the expected sign but are imprecisely estimated. The coefficients on EC and $\mathrm{pH}$ greater than 7.5 have the opposite sign as expected, but are not statistically significant. The state fixed effects may also capture some of the variation in soil characteristics across states.

It is also important to recognize that the water holding capacity of the soil has a major impact on rent and is accounted for in measures of water deficit and surplus. For example, soils in Knox County, Missouri have an average water holding capacity of 6.3 inches compared to 10.7 inches in Hancock County, Illinois. Both counties have very similar growing season precipitation-23.0 inches in Knox and 22.8 inches in Hancock-but the water deficit is 7.2 inches in Knox compared to 5.3 inches in Hancock. The regression results suggest that rents are $\$ 24$ /acre lower in Knox county due to the greater water deficit.

\footnotetext{
${ }^{17}$ Allowing the increase in temperature to affect all climate variables, I find an overall decrease in rents of $14.1 \%$. My estimates of the damages are similar to Schlenker and Roberts (2009) who find that a $2^{\circ} \mathrm{C}$ increase in temperature decreases corn yield by $14.9 \%$. Note that the impacts through the two mechanisms do not add up to the overall impact due to the functional form.
} 


\subsection{Estimates of Damages and Uncertainty}

Next, I estimate the damages under future climate scenarios by coupling the climate projections with the econometric model. To calculate the relative change in rent due to climate change, I compare the aggregate rents using historical climate data and projected climate data. Aggregate rents are calculated by predicting the rental rate per acre in each county, multiplying rent by nonirrigated cropland acres, and summing total rent across all counties. ${ }^{18}$ Rental rate data are missing for some counties in my data (see figure 1), but I have complete coverage for climate and soils data. I predict the change in rents in my simulations even for those counties with missing rent data using nonmissing climate and soil data.

Next, I estimate the relative change in rents by each source of damages: (i) water deficit, (ii) water surplus, and (iii) heat stress. To estimate the damages due to water deficit, I simulate rents using the projected water deficit and hold constant water surplus, GDDs, and EDDs. A similar procedure is used for water surplus. The damages from heat stress reflect projected changes in both GDDs and EDDs.

Importantly, I also quantify the uncertainty in my estimates of damages and the source of damages. To estimate uncertainty due to the regression estimation alone, I use a cluster bootstrap with 1,000 replications where I cluster by state. I use the wild bootstrap, which preserves the regressors but resamples the dependent variable using the OLS prediction and the residual with probability 0.5 and the negative of the residual with probability 0.5 . Bootstrap methods that resample the regressors can be problematic when there are few clusters (Cameron, Gelbach and Miller 2008). I use the ensemble average climate projection in each of the bootstrap replications in order to quantify the impact of econometric uncertainty alone.

The uncertainty in damages due to uncertainty in future climate projections are quantified by estimating damages separately for the projections of each of the 18 climate models. Following Burke et al. (2014), I quantify the uncertainty from both the regression model and the climate models by combining the estimates from bootstrap replications across all climate models for a total of 18,000 replications.

Figure 4 illustrates the projected damages by each mechanism and the source of uncertainty. The number in each plot indicates the relative change in rent with ensemble average projections. The middle line in each box plot shows the median estimate, the upper and lower bounds of the box show the upper and lower quartiles, and the upper and lower bounds

\footnotetext{
${ }^{18}$ Alternatively, I could calculate the change in log rental rate using the aggregate predicted rental rate weighted by cropland area in each county. Changes in logs only approximate percent changes well for small changes in the variable and in my case there becomes a substantial difference between the percent change in predicted rents and the change in the log of predicted rents.
} 
of the line show the 90 percent confidence interval. The $90 \%$ confidence interval for climate uncertainty represents the entire range of estimates across the different climate models since there are 18 climate models.

Nonirrigated rents are estimated to decrease by $33 \%$ or roughly $\$ 9.5$ billion by midcentury (figure 4). My results of large damages support the argument of Auffhammer and Schlenker (2013) that well-specified econometric models using cross-sectional and panel data both indicate large negative economic impacts for U.S. agriculture, in contrast to the argument of Seo (2013). An increase in water deficit alone results in a $12 \%$ decrease in rents, changes in water surplus has little impact, and changes in heat stress alone decreases rents by $23 \%$. These results imply that roughly $32 \%$ of projected damages are due to water deficit, $3 \%$ due to water surplus, and $65 \%$ due to heat stress. ${ }^{19}$ The importance of heat stress in climate change damages is partly because of the importance of heat stress for agricultural rents but also due to the large projected increase in heat stress due to climate change. It is also interesting that climate change has a larger impact on rent through heat stress rather than water stress even thought a $2^{\circ} \mathrm{C}$ increase in temperature has a larger impact through water stress. The difference in result occurs because the temperature increase under climate change is not spatially or temporally uniform and precipitation changes as well.

These estimates do not reflect the effects of greater $\mathrm{CO}_{2}$ on water use efficiency of crops. In particular, $\mathrm{CO}_{2}$ fertilization implies that total damages are smaller and a greater proportion of damages are due to heat stress. There is, however, evidence that the $\mathrm{CO}_{2}$ effect may be smaller than once thought (Long et al. 2006). One estimate indicates that the damages from water stress would decrease by at most 25\% (Lobell et al. 2013).

The majority of uncertainty about future damages from climate change arise due to uncertainty across climate models (figure 4). The total projected change in rents range from a decrease of $55.2 \%$ to an increase of $11.7 \%$. The ACCESS1-0 climate model results in the most negative change in rents and MRI-CGCM3 indicates the most positive change in rents (see table A2 for a list of climate models). But excluding just three of the climate models gives a range of projected change in rents of $-43.5 \%$ to $-14.8 \%$.

Comparing uncertainty about the source of damages indicates that there is slightly more regression and climate uncertainty regarding heat stress than water stress. The larger regression uncertainty from heat stress is in part due to the larger projected increase in heat stress

\footnotetext{
${ }^{19}$ Summing the relative change in rents across sources does not equal the relative change in total rents due to the log functional form. Therefore, when calculating the share of damages due to each source, I estimate the change in the log of aggregate rents. The share of damages due to a particular source is the change in $\log$ rents due to that source divided by the change in log rents accounting for all three sources. The shares nearly add to one when calculating the share of damages in this way even though the change in logs does not exactly equal the relative change in rents (see footnote 18).
} 
rather than greater uncertainty in the econometric model (i.e., the regression coefficients for EDDs are multiplied by larger changes). Although increases in water deficit are expected to decrease rents by about $12 \%$ with the ensemble average projections, rents could decrease by as much as $29 \%$ according to the ACCESS1-0 climate model or increase by $6 \%$ according to the CNRM-CM5 climate model. And although increases in heat stress are expected to decrease rents by about $23 \%$ with the ensemble average projections, rents could decrease by $39 \%$ according to the ACCESS1-0 climate model or increase by $10 \%$ according to the MRI-CGCM3 climate model.

To examine the impact of incorporating water deficit and water surplus in the econometric model, I consider an alternative specification where I include precipitation instead and water holding capacity of the soil is included as a control (i.e., the traditional model). I use the same cross-validation procedure to select the optimal number of spline knots for precipitation, GDDs, and EDDs. The total damages from projected climate change are similar with the traditional model (35\% decrease in rents). The traditional model indicates a negligible decrease in rents $(-0.02 \%)$ due to changes in precipitation so that all of the damages are due to changes in temperature. ${ }^{20,21}$ The portion of damages from temperature increases that occur through heat and water stress are not identified in the traditional model. Therefore, the primary advantage of incorporating a water balance into the econometric model is the ability to separately identify the damages from heat and water stress and not in providing an improved estimate of overall damages. Understanding the mechanism of damages is critical, however, for assessing potential adaptation mechanisms.

\subsection{Spatial Distribution of Damages}

The spatial distribution of the damages are shown in figure 5 (color figures are available in the online version of this article). The impact on rents in each county depends on the spatial distribution of projected climate change (figure A6 in the supplementary appendix) and the nonlinear response of rents to changes in climatic variables (figure 3). The damages from

\footnotetext{
${ }^{20}$ The ensemble average climate projection indicates that precipitation will increase in some counties by as much as 1.0 inch and decrease in others by as much as 0.8 inches. The average change in precipitation across all counties is 0.04 inches. This could lead to substantial damages if wet regions are expected to get wetter and dry regions are expected to get drier. However, climate projections indicate that Northern states are likely to get wetter - even in the western regions where additional rainfall would be beneficial (see figure A7 in the supplementary appendix). Even though climate projections indicate negligible changes in precipitation across counties on average, projections are consistent with a large increase in water deficit because greater average temperatures in the future result in greater ET demand and thus greater water deficit. On average, water deficit is expected to increase by 2.4 inches across all counties, with an increase of nearly 4 inches of deficit in some counties.

${ }^{21} \mathrm{My}$ results of the precipitation model are similar to the results of Schlenker, Hanemann and Fisher (2006) who estimate that the change in farmland value due to projected changes in precipitation are between $-6 \%$ and $+9 \%$, but most often near zero.
} 
climate change - and thus the potential benefits from innovations to offset climate change damages - are largest in the central Corn Belt. This area has the largest relative change in rents due to climate change as well as some of the highest initial nonirrigated rental rates.

The spatial distribution of the damages through the different mechanisms are starkly different (figure 5). Since log rent is linear in water deficit, the variation in relative damages corresponds with the spatial distribution of projected climate change, with the largest increase in deficit projected to occur in the Plains region (see figure A6). Every county is expected to suffer losses due to increases in water deficit. Damages are generally small from changes in water surplus but are largest in counties in the southeast portion of the sample with generally greater precipitation and projected increases in precipitation in the future.

The central Corn Belt is expected to have the largest damages from heat stress because the largest damages from an increase in EDDs occurs in areas with a relatively small number of initial EDDs (figure 5). Even though EDDs are expected to increase the most in the Southern Plains, this region already has a large exposure to EDDs and is not expected to incur large additional damages. Some counties in the northern states benefit from greater heat that increases GDDs but this positive effect is minimal compared to the large losses elsewhere.

\subsection{Placebo Test and Robustness Checks}

Table 3 shows projected climate damages by source for nonirrigated and irrigated cash rental rates. The results for nonirrigated rent are the same as the main specification in figure 4 and irrigated results use the irrigated cash rental rate as the dependent variable. Comparing the irrigated results to the nonirrigated results represents a placebo test for the effect of water deficit. Irrigation should reduce the effect of water deficit - although irrigation may not completely eliminate the effect of water deficit since greater water deficit means that farmers incur an additional cost to pump water and irrigation water availability may be limited in some regions. Finding a significant impact of water deficit on irrigated rents would create concerns that my results for nonirrigated rents simply represent a spurious correlation. The results in table 3 support my main specification since water deficit has a small and statistically insignificant impact on irrigated rents. ${ }^{22}$ The supplementary appendix contains a map of irrigated rental rates (figure A8), the impact of each climate variable on irrigated rents (figure A9), and a map of projected irrigated damages (figure A10).

Of course the impacts of climate change on irrigated agriculture are also of interest (Tack, Barkley and Hendricks 2017). However, the results for irrigation in table 3 should be

\footnotetext{
${ }^{22}$ The coefficient on water deficit in the regression model for irrigated rents (not reported) is also statistically insignificant.
} 
interpreted with caution because the availability and cost of surface and groundwater are not controlled for in the regression. The results are biased to the extent that these omitted variables are correlated with climate. For example, there has been greater depletion of the southern portion of the High Plains Aquifer (i.e., Ogallala Aquifer) and temperatures are higher in the south as well (Steward and Allen 2016).

I also consider several alternative specification to test the robustness of the damage estimates and the source of damages. The first column in table A5 in the supplementary appendix shows results from the post-double-selection procedure described earlier in this paper which is designed to reduce concerns about omitted variable bias. The results are similar to my preferred estimates.

The second column of table A5 omits all counties where greater than $10 \%$ of cropland area was planted to winter wheat (see figure A11 for a map of winter wheat area). The number of counties in the regression decreases from 942 to 691. One concern with including winter wheat in the main specification is that climate variables were calculated for April 1-September 31, which does not capture the full growing season for winter wheat. Results omitting winter wheat counties, however, are similar to the main specification. The advantage of including winter wheat counties is that switching to winter wheat may be one way farmers adjust to different climates so it is preferable to account for this option when estimating damages.

The third column of table A5 includes linear terms for off-season (October 1 of the previous year to March 31) water deficit and water surplus in the regression and projected climate change. Precipitation during this period is also accounted for in the growing-season water deficit and surplus through its effect on soil moisture. However, off-season water deficit and surplus could be important for winter wheat production. The regression coefficients on these variables (not shown in a table) were not statistically significant and projected climate change damages are similar to my preferred estimates.

The fourth column of table A5 shows results when I include an interaction term between water deficit and EDDs. My preferred model specification captures an interaction between temperature and precipitation since water deficit has a nonlinear impact on rents, so higher temperatures have a different impact in regions with different amounts of precipitation. ${ }^{23} \mathrm{I}$ include an interaction term to add even more flexibility to the specification. The coefficient on the interaction term indicates that EDDs have a less negative impact in regions with greater water deficit-opposite of the expected result-but the interaction is statistically

\footnotetext{
${ }^{23}$ Fezzi and Bateman (2015) motivate an interaction term in their model by noting that higher temperatures increase ET and thus increases water demand for crop development. This effect is captured in my water balance model.
} 
insignificant and the predicted damages from climate change are similar to my preferred estimates.

Table A6 in the supplementary appendix shows that results are robust to using different years of rental rate data (2009-2012) to estimate the Ricardian rent function. Rental rates were first reported in 2008, but the sample size was much smaller than for other years so I only estimate the model with data from 2009 or after.

Table A7 in the supplementary appendix shows results with alternative temperature thresholds for calculating EDDs. Using a lower temperature threshold to construct EDDs results in greater predicted damages with a larger proportion of damages attributed to heat stress. For example, a threshold of $32^{\circ} \mathrm{C}$ indicates an overall decrease in rents of $39 \%$ due to climate change and $76 \%$ of the damages are due to heat stress. A threshold of $36^{\circ} \mathrm{C}$ indicates an overall decrease in rents of $24 \%$ due to climate change and $44 \%$ of the damages are due to heat stress. However, I prefer the specification that calculates EDDs using $34^{\circ} \mathrm{C}$ as the threshold since this threshold provides the best fit according to cross-validation. Greater water stress at higher temperatures may lead some articles to find that temperatures greater than $30^{\circ} \mathrm{C}$ are harmful to crop production (Lobell et al. 2013), but I account for this negative effect by including ET in the water balance model.

The results are also robust to allowing the coefficients on climate to vary by soil textures. In my main specification, marginal effects of a change in climate are heterogeneous across space due to the nonlinear specification. Dall'erba and Domínguez (2016) allow coefficients in a Ricardian model of the Southwestern U.S. to differ for counties with high elevation versus low elevation. Coefficients are not likely to differ by elevation in my sample since I do not include a mountainous region in my data but it could be that the coefficients of the nonlinear functions differ across soil types if certain soils are more susceptible to climate stress. I interact each of the nonlinear functions of climate variables with the proportion of the county classified as sandy soil and the proportion classified as clay soils (proportion classified as silt is omitted). The estimates of damages due to climate change by each source (table A8) and the map of damages (figure A12) are similar to my main specification.

\section{Policy Implications}

Policymakers and scientists must decide how to allocate R\&D expenditures between innovations to reduce heat stress (e.g., heat tolerant crop varieties) or water stress (e.g., drought tolerant crop varieties). The economically optimal allocation of expenditures depends on the benefits and costs of innovations to reduce each type of stress. My results estimate the 
potential benefits from these innovations, but it is beyond the scope of this paper to estimate costs of the innovations.

The estimated rent functions in figure 3 quantify the economic benefits from reductions in each type of stress - even in the absence of climate change. Innovations that reduce the effective water deficit should have roughly the same relative benefit across space, but a greater absolute benefit in areas with higher initial cash rents. Innovations that increase heat tolerance have the greatest potential benefit in regions with relatively fewer EDDs.

Estimates of damages from climate change in figures 4-5 indicate the potential economic benefits of climate change adaptation through innovations that offset the damages. My estimates indicate large potential benefits from innovations to reduce climate change damages and thus suggest that an increase in R\&D investments in agriculture is likely justifiedthough I cannot quantify the costs of $R \& D$ to reduce these damages. There is a large amount of uncertainty in damages mostly due to varying projections across climate models. However, rents are expected to decline in nearly every scenario-decreasing by $55 \%$ according to one climate model - thus providing a rationale for $\mathrm{R} \& \mathrm{D}$ expenditures for climate change adaptation.

Even though water deficit has a large impact on rents, I find that a majority of the damages from projected climate change are due to heat stress rather than water deficit or water surplus. Heat stress is especially important for climate change adaptation due to the large projected increase in heat stress. Assuming that the cost of innovations are roughly the same for heat and water stress, increases in R\&D investments should focus relatively more on reducing heat stress.

The spatial distribution of damages indicates that the optimal portfolio of R\&D investments to offset climate change damages varies spatially (figure 5). Research to reduce water stress is of relatively greater priority in the Plains and research in the central Corn Belt should focus primarily on reducing heat stress. The overall potential gains from innovations to offset climate damages are largest in the central Corn Belt - an area with the largest projected change in relative rents as well as some of the highest initial nonirrigated rents.

\section{Conclusion}

The primary contribution of this paper is to separately identify the impacts of heat and water stress by incorporating measures of water deficit and water surplus from a water balance model into an econometric model explaining agricultural rental rates. Another important contribution is to advance the Ricardian approach by taking several steps to reduce concerns about omitted variable bias. I also use the best practice methodology of quantifying the 
uncertainty of my estimates due to uncertainty in the regression estimates and uncertainty in climate projections (Burke et al. 2014).

I estimate that agricultural nonirrigated rents could decrease by $33 \%$ ( $\$ 9.5$ billion) in the central United States by mid-century. Uncertainty in damages due to climate projections $(90 \%$ CI $[-55.2 \%, 11.7 \%])$ is much larger than uncertainty due to regression estimates $(90 \%$ CI $[-38.5 \%,-27.1 \%])$. Assuming a similar cost of innovations to mitigate each type of stress, my results indicate additional $R \& D$ effort should focus mostly on reducing heat stress but the optimal investment portfolio varies spatially. Results also indicate that while previous statistical methodologies give similar estimates of the overall damages, they are not able to identify how much of the damages occur through water stress versus heat stress.

There are several important caveats to my analysis. First, my estimates of the damages are valid for the prices used when farmers negotiated 2013 cash rental rates. If climate change reduces global crop production, then prices may increase and I overestimate the damages. Second, while my estimates reflect adaptation by adjusting production practices currently available, they do not reflect the cost of adjustment (Quiggin and Horowitz 1999; Kelly, Kolstad and Mitchell 2005). However, these costs are likely small in my sample where the majority of nonirrigated cropland is planted to a few field crops with relatively similar production practices. Third, my estimates quantify the effect of changes in average climatic conditions, but do not quantify the effect of changes in the variability of weather or extreme events.

There are many important areas for future research. One important area of research is to quantify the costs of innovations to offset heat versus water stress. Another area for future research is to understand how government subsidies could interact with climate change. For example, subsidized crop insurance may reduce the incentive to adapt to climate change (Annan and Schlenker 2015; Chen and Dall'Erba 2017). A key empirical challenge in studying the impacts of government programs is to exploit exogenous variability since program intensity is correlated with land productivity. Another important topic for future research is to better understand how technology might change through the private market due to climate change. I have focused on estimating the potential benefits from public R\&D to offset climate change damages, however, the private market may also respond to the incentives and innovate new technologies that offset the damages. 


\section{References}

Adams, Richard M., Cynthia Rosenzweig, Robert M. Peart, Joe T. Ritchie, Bruce A. McCarl, J. David Glyer, R. Bruce Curry, James W. Jones, Kenneth J. Boote, and L. Hartwell Allen. 1990. "Global climate change and US agriculture." Nature, 345(6272): 219-224.

Allen, Richard G., Luis S. Pereira, Dirk Raes, and Martin Smith. 1998. "Crop evapotranspiration: Guidelines for computing crop requirements." FAO Irrigation and Drainage Paper 56, Rome, Italy.

Annan, Francis, and Wolfram Schlenker. 2015. "Federal crop insurance and the disincentive to adapt to extreme heat." American Economic Review, 105(5): 262-266.

Auffhammer, Maximilian, and Wolfram Schlenker. 2013. "It's not just the statistical model. A comment on Seo (2013)." Climatic Change, 121(2): 125-128.

Auffhammer, Maximilian, Solomon M. Hsiang, Wolfram Schlenker, and Adam Sobel. 2013. "Using weather data and climate model output in economic analyses of climate change." Review of Environmental Economics and Policy, 7(2): 181-198.

Belloni, Alexandre, Victor Chernozhukov, and Christian Hansen. 2014. "Inference on treatment effects after selection among high-dimensional controls." The Review of Economic Studies, 81(2): 608-650.

Bester, C. Alan, Timothy G. Conley, and Christian B. Hansen. 2011. "Inference with dependent data using cluster covariance estimators." Journal of Econometrics, 165(2): 137-151.

Borchers, Allison, Jennifer Ifft, and Todd Kuethe. 2014. "Linking the price of agricultural land to use values and amenities." American Journal of Agricultural Economics, 96(5): 1307-1320.

Burke, Marshall, and Kyle Emerick. 2016. "Adaptation to climate change: Evidence from US agriculture." American Economic Journal: Economic Policy, 8(3): 106-140.

Burke, Marshall, John Dykema, David B. Lobell, Edward Miguel, and Shanker Satyanath. 2014. "Incorporating climate uncertainty into estimates of climate change impacts." Review of Economics and Statistics, 97(2): 461-471. 
Cameron, A. Colin, Jonah B. Gelbach, and Douglas L. Miller. 2008. "Bootstrapbased improvements for inference with clustered errors." Review of Economics and Statistics, 90(3): 414-427.

Chen, Shuai, Xiaoguang Chen, and Jintao Xu. 2016. "Impacts of climate change on agriculture: Evidence from China." Journal of Environmental Economics and Management, 76: 105-124.

Chen, Zhangliang, and Sandy Dall'Erba. 2017. "Do crop insurance programs preclude their recipients from adapting to new climate conditions?" Discussion Paper of the Regional Economics Applications Laboratory, University of Illinois at Urbana-Champaign.

Costinot, Arnaud, Dave Donaldson, and Cory Smith. 2016. "Evolving comparative advantage and the impact of climate change in agricultural markets: Evidence from 1.7 million fields around the world." Journal of Political Economy, 124(1): 205-248.

Dall'erba, Sandy, and Francina Domínguez. 2016. "The impact of climate change on agriculture in the Southwestern United States: The ricardian approach revisited." Spatial Economic Analysis, 11(1): 46-66.

Dell, Melissa, Benjamin F. Jones, and Benjamin A. Olken. 2014. "What do we learn from the weather? The new climate-economy literature." Journal of Economic Literature, 52(3): 740-98.

Deryng, Delphine, Declan Conway, Navin Ramankutty, Jeff Price, and Rachel Warren. 2014. "Global crop yield response to extreme heat stress under multiple climate change futures." Environmental Research Letters, 9(3): 034011.

Featherstone, Allen M., and Timothy G. Baker. 1987. "An examination of farm sector real asset dynamics: 1910-85." American Journal of Agricultural Economics, 69(3): 532546.

Fereres, Elias, and María Auxiliadora Soriano. 2007. "Deficit irrigation for reducing agricultural water use." Journal of Experimental Botany, 58(2): 147-159.

Fezzi, Carlo, and Ian Bateman. 2015. "The impact of climate change on agriculture: Nonlinear effects and aggregation bias in ricardian models of farmland values." Journal of the Association of Environmental and Resource Economists, 2(1): 57-92.

Fisher, Anthony C., W. Michael Hanemann, Michael J. Roberts, and Wolfram Schlenker. 2012. "The economic impacts of climate change: Evidence from agricultural 
output and random fluctuations in weather: Comment." American Economic Review, 102(7): 3749-60.

Hatfield, J. L., K. J. Boote, B. A. Kimball, L. H. Ziska, R. C. Izaurralde, D. Ort, A. M. Thomson, and D. Wolfe. 2011. "Climate impacts on agriculture: Implications for crop production." Agronomy Journal, 103(2): 351-370.

Howden, S. Mark, Jean-François Soussana, Francesco N. Tubiello, Netra Chhetri, Michael Dunlop, and Holger Meinke. 2007. "Adapting agriculture to climate change." Proceedings of the National Academy of Sciences, 104(50): 19691-19696.

Huang, Jikun, Yangjie Wang, and Jinxia Wang. 2015. "Farmers' adaptation to extreme weather events through farm management and its impacts on the mean and risk of rice yield in China." American Journal of Agricultural Economics, 97(2): 602-617.

Just, Richard E., and John A. Miranowski. 1993. "Understanding farmland price changes." American Journal of Agricultural Economics, 75(1): 156-168.

Kelejian, Harry H., and Ingmar R. Prucha. 2010. "Specification and estimation of spatial autoregressive models with autoregressive and heteroskedastic disturbances." Journal of Econometrics, 157(1): 53-67.

Kelly, David L., Charles D. Kolstad, and Glenn T. Mitchell. 2005. "Adjustment costs from environmental change." Journal of Environmental Economics and Management, $50(3): 468-495$.

Kirwan, Barrett E. 2009. "The incidence of US agricultural subsidies on farmland rental rates." Journal of Political Economy, 117(1): 138-164.

Klingebiel, A. A., and P. H. Montgomery. 1961. "Land-capability classification." Soil Conservation Service, USDA Agricultural Handbook 210.

Lobell, David B. 2014. "Climate change adaptation in crop production: Beware of illusions." Global Food Security, 3(2): $72-76$.

Lobell, David B, Graeme L Hammer, Greg McLean, Carlos Messina, Michael J Roberts, and Wolfram Schlenker. 2013. "The critical role of extreme heat for maize production in the United States." Nature Climate Change, 3: 497-501.

Lobell, David B, Marianne Bänziger, Cosmos Magorokosho, and Bindiganavile Vivek. 2011. "Nonlinear heat effects on African maize as evidenced by historical yield trials." Nature Climate Change, 1(1): 42-45. 
Lobell, David B., Marshall B. Burke, Claudia Tebaldi, Michael D. Mastrandrea, Walter P. Falcon, and Rosamond L. Naylor. 2008. "Prioritizing climate change adaptation needs for food security in 2030." Science, 319(5863): 607-610.

Long, Stephen P., Elizabeth A. Ainsworth, Andrew D. B. Leakey, Josef Näsberger, and Donald R. Ort. 2006. "Food for thought: Lower-than-expected crop yield stimulation with rising CO2 concentrations." Science, 312(5782): 1918-1921.

Massetti, Emanuele, and Robert Mendelsohn. 2011. "Estimating ricardian models with panel data." Climate Change Economics, 02(04): 301-319.

Mendelsohn, Robert O, and Ariel Dinar. 2009. Climate change and agriculture: An economic analysis of global impacts, adaptation and distributional effects. Northampton, MA:Edward Elgar Publishing.

Mendelsohn, Robert, William D. Nordhaus, and Daigee Shaw. 1994. "The impact of global warming on agriculture: A ricardian analysis." American Economic Review, 84(4): 753-771.

Moss, Richard H, Jae A Edmonds, Kathy A Hibbard, Martin R Manning, Steven K Rose, Detlef P Van Vuuren, Timothy R Carter, Seita Emori, Mikiko Kainuma, Tom Kram, G. A. Meehl, J.F.B. Mitchell, N. Nakicenovic, K. Riahi, S.J. Smith, R.J. Stouffer, A.M. Thomson, J.P. Weyant, and T.J. Wilbanks. 2010. "The next generation of scenarios for climate change research and assessment." $N a-$ ture, 463(7282): 747-756.

NRCS, USDA. 2015. "Soil quality indicator sheets." Accessed June 10, 2015. Available at http://www.nrcs.usda.gov/wps/portal/nrcs/detail/soils/health/assessment/ ?cid=stelprdb1237387.

Olmstead, Alan L., and Paul W. Rhode. 2011. "Adapting North American wheat production to climatic challenges 1839-2009." Proceedings of the National Academy of Sciences, 108(2): 480-485.

Ortiz-Bobea, Ariel, and Richard E. Just. 2013. "Modeling the structure of adaptation in climate change impact assessment." American Journal of Agricultural Economics, 95(2): 244-251.

Plantinga, Andrew J., and Douglas J. Miller. 2001. "Agricultural land values and the value of rights to future land development." Land Economics, 77(1): 56-67. 
Polsky, Colin. 2004. "Putting space and time in ricardian climate change impact studies: Agriculture in the U.S. Great Plains, 1969-1992." Annals of the Association of American Geographers, 94(3): 549-564.

Porter, John R., Liyong Xie, Andrew J. Challinor, Kevern Cochrane, S. Mark Howden, Muhammad M. Iqbal, David B. Lobell, and Maria I. Travasso. 2014. "Food security and food production systems." In Climate change 2014: Impacts, adaptation, and vulnerability. Part A: global and sectoral aspects. Contribution of working group II to the fifth assessment report of the Intergovernmental Panel on Climate Change. , ed. Christopher B. Field, Vicente R. Barros, David J. Dokken, Katharine J. Mach, Michael D. Mastrandrea, T. Eren Bilir, Monalisa Chatterjee, Kristie L. Ebi, Yuko O. Estrada, Robert C. Genova, Betelhem Girma, Eric S. Kissel, Andrew N. Levy, Sandy MacCracken, Patricia R. Mastrandrea and Leslie L. White, 485-533. United Kingdom and New York, NY:Cambridge University Press.

Pray, Carl E., and Keith O. Fuglie. 2015. "Agricultural research by the private sector." Annual Review of Resource Economics, 7(1): 399-424.

Quiggin, John, and John K. Horowitz. 1999. "The impact of global warming on agriculture: A ricardian analysis: Comment." American Economic Review, 89(4): 1044-1045.

Reclamation. 2013. "Downscaled CMIP3 and CMIP5 climate and hydrology projections: Release of downscaled CMIP5 climate projections, comparison with preceding information, and summary of user needs." Prepared by the U.S. Department of the Interior, Bureau of Reclamation, Technical Services Center, Denver, Colorado.

Reilly, John, and Neil Hohmann. 1993. "Climate change and agriculture: The role of international trade." American Economic Review, 83(2): 306-312.

Ritchie, J. T., and D. S. Nesmith. 1991. "Temperature and crop development." In Modeling Plant and Soil Systems. 5-29. Madison, WI:American Society of Agronomy.

Rosenzweig, Cynthia, and Daniel Hillel. 1998. Climate change and the global harvest: Potential impacts of the greenhouse effect on agriculture. New York:Oxford University Press.

Rosenzweig, Cynthia, and Martin L. Parry. 1994. "Potential Impact of Climate Change on World Food Supply." Nature, 367(6459): 133-138.

Schauberger, Bernhard, Sotirios Archontoulis, Almut Arneth, Juraj Balkovic, Philippe Ciais, Delphine Deryng, Joshua Elliott, Christian Folberth, Nikolay 
Khabarov, Christoph Müller, Thomas A M Pugh, Susanne Rolinski, Sibyll Schaphoff, Erwin Schmid, Xuhui Wang, Wolfram Schlenker, and Katja Frieler. 2017. "Consistent negative response of US crops to high temperatures in observations and crop models." Nature Communications, 8: 13931.

Schlenker, Wolfram, and Michael J. Roberts. 2009. "Nonlinear temperature effects indicate severe damages to U.S. crop yields under climate change." Proceedings of the National Academy of Sciences, 106(37): 15594-15598.

Schlenker, Wolfram, W. Michael Hanemann, and Anthony C. Fisher. 2005. "Will U.S. agriculture really benefit from global warming? Accounting for irrigation in the hedonic approach." American Economic Review, 95(1): 395-406.

Schlenker, Wolfram, W. Michael Hanemann, and Anthony C. Fisher. 2006. "The impact of global warming on U.S. agriculture: An econometric analysis of optimal growing conditions." Review of Economics and Statistics, 88(1): 113-125.

Seo, S. Niggol. 2013. "An essay on the impact of climate change on US agriculture: Weather fluctuations, climatic shifts, and adaptation strategies." Climatic Change, 121(2): 115-124.

Seo, S.Niggol, Robert Mendelsohn, Ariel Dinar, Rashid Hassan, and Pradeep Kurukulasuriya. 2009. "A ricardian analysis of the distribution of climate change impacts on agriculture across agro-ecological zones in Africa." Environmental and Resource Economics, 43(3): 313-332.

Singh, Piara, S. Nedumaran, P.C.S. Traore, K.J. Boote, H.F.W. Rattunde, P.V. Vara Prasad, N.P. Singh, K. Srinivas, and M.C.S. Bantilan. 2014. "Quantifying potential benefits of drought and heat tolerance in rainy season sorghum for adapting to climate change." Agricultural and Forest Meteorology, 185: 37 - 48.

Snyder, R.L. 1985. "Hand calculating degree days." Agricultural and Forest Meteorology, 35(1): $353-358$.

Stephenson, Nathan L. 1990. "Climatic control of vegetation distribution: The role of the water balance." The American Naturalist, 135(5): 649-670.

Steward, David R., and Andrew J. Allen. 2016. "Peak groundwater depletion in the High Plains Aquifer, Projections from 1930 to 2110." Agricultural Water Management, 170: $36-48$. 
Tack, Jesse, Andrew Barkley, and Lawton Lanier Nalley. 2015. "Effect of warming temperatures on US wheat yields." Proceedings of the National Academy of Sciences, 112(22): 6931-6936.

Tack, Jesse, Andrew Barkley, and Nathan Hendricks. 2017. "Irrigation offsets wheat yield reductions from warming temperatures." Environmental Research Letters, 12(11): 114027 .

Thornthwaite, C. W. 1948. "An approach toward a rational classification of climate." Geographical Review, 38(1): 55-94.

Towe, Charles, and Constant I. Tra. 2013. "Vegetable spirits and energy policy." American Journal of Agricultural Economics, 95(1): 1-16.

Welch, Jarrod R., Jeffrey R. Vincent, Maximilian Auffhammer, Piedad F. Moya, Achim Dobermann, and David Dawe. 2010. "Rice yields in tropical/subtropical Asia exhibit large but opposing sensitivities to minimum and maximum temperatures." Proceedings of the National Academy of Sciences, 107(33): 14562-14567.

Woodard, Joshua D. 2016. "Data science and management for large scale empirical applications in agricultural and applied economics research." Applied Economic Perspectives and Policy, 38(3): 373-388. 


\section{Tables}

Table 1: Mean and Standard Deviation for Variables in the Econometric Analysis

\begin{tabular}{lcc}
\hline & Mean & Std. Dev. \\
\hline Cash Rent (\$/acre) & 122.44 & 82.30 \\
Log of Cash Rent & 4.50 & 0.87 \\
Water Deficit (in) & 10.92 & 7.06 \\
Water Surplus (in) & 0.83 & 0.96 \\
Hundreds of Growing Degree Days - GDD & 17.43 & 3.67 \\
Extreme Degree Days - EDD & 7.38 & 10.72 \\
Soil Organic Carbon (kg/m²) - SOC & 13.37 & 5.43 \\
Bulk Density & 1.43 & 0.06 \\
Electrical conductivity - EC & 0.48 & 0.69 \\
pH Less than 6 & 0.14 & 0.23 \\
pH Greater than 7.5 & 0.32 & 0.38 \\
Log of Slope & 1.01 & 0.64 \\
\hline
\end{tabular}


Table 2: Regression Coefficients for the Ricardian Rent Function

\begin{tabular}{|c|c|}
\hline & Coefficients \\
\hline \multirow[t]{2}{*}{ Water Deficit } & $-0.058^{* *}$ \\
\hline & $(0.017)$ \\
\hline \multirow[t]{2}{*}{ Water Surplus } & $-0.168 * *$ \\
\hline & $(0.035)$ \\
\hline \multirow[t]{2}{*}{ GDD Spline 1} & $0.307 * *$ \\
\hline & $(0.042)$ \\
\hline \multirow{2}{*}{ GDD Spline 2} & $-0.316^{* *}$ \\
\hline & $(0.058)$ \\
\hline \multirow[t]{2}{*}{ EDD Spline 1} & $-0.181^{* *}$ \\
\hline & $(0.024)$ \\
\hline \multirow[t]{2}{*}{ EDD Spline 2} & $0.515^{* *}$ \\
\hline & $(0.056)$ \\
\hline \multirow[t]{2}{*}{$\mathrm{SOC}$} & 0.001 \\
\hline & $(0.003)$ \\
\hline \multirow[t]{2}{*}{ Bulk Density } & -0.285 \\
\hline & $(0.540)$ \\
\hline \multirow[t]{2}{*}{$\mathrm{EC}$} & 0.013 \\
\hline & $(0.038)$ \\
\hline \multirow[t]{2}{*}{ pH Less than 6} & $-0.140^{*}$ \\
\hline & $(0.076)$ \\
\hline \multirow[t]{2}{*}{ pH Greater than 7.5} & 0.168 \\
\hline & $(0.121)$ \\
\hline \multirow[t]{2}{*}{ Log of Slope } & $-0.082^{*}$ \\
\hline & $(0.046)$ \\
\hline \multirow[t]{2}{*}{ Constant } & 1.543 \\
\hline & $(1.269)$ \\
\hline State Fixed Effects & Yes \\
\hline Observations & 942 \\
\hline$R^{2}$ & 0.926 \\
\hline
\end{tabular}

Note. Standard errors in parentheses.

* $\mathrm{p}<0.10$.

$* * \mathrm{p}<0.05$. 
Table 3: Relative Change in Nonirrigated and Irrigated Rental Rates due to Climate Change

\begin{tabular}{lcc}
\hline & Nonirrigated & Irrigated \\
\hline Total & $-0.33^{* *}$ & $-0.36^{* *}$ \\
Water Deficit & $(0.035)$ & $(0.021)$ \\
& $-0.12^{* *}$ & 0.03 \\
Water Surplus & $(0.032)$ & $(0.047)$ \\
& $-0.01^{* *}$ & -0.004 \\
Heat Stress & $(0.003)$ & $(0.003)$ \\
& $-0.23^{* *}$ & $-0.37^{* *}$ \\
Observations in Regression & $(0.056)$ & $(0.033)$ \\
\hline
\end{tabular}

Note. Standard errors in parentheses represents the uncertainty from the regression model alone.

$* \mathrm{p}<0.10$.

** $\mathrm{p}<0.05$. 
Figures

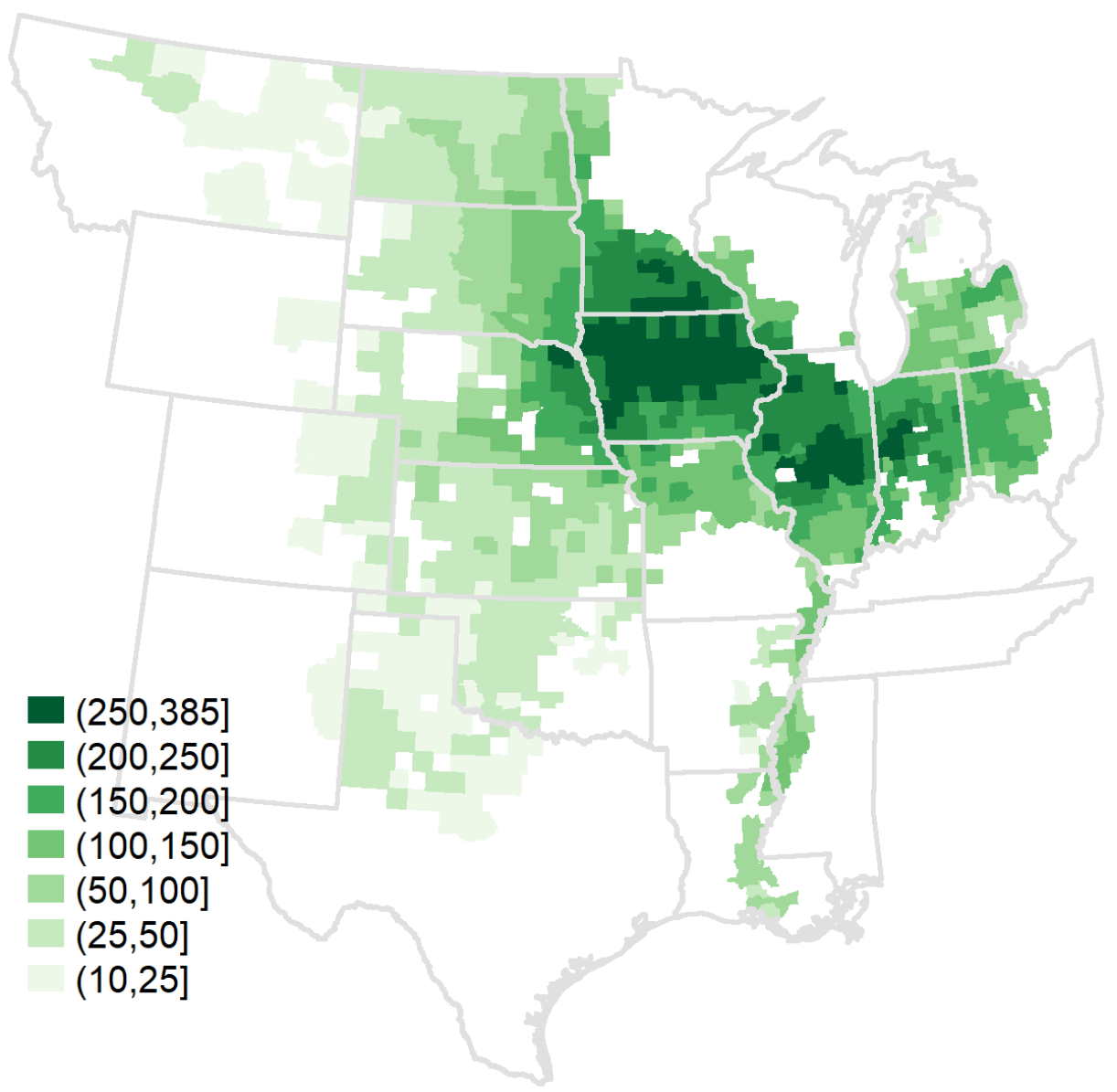

Figure 1: Nonirrigated Cash Rental Rates in 2013 

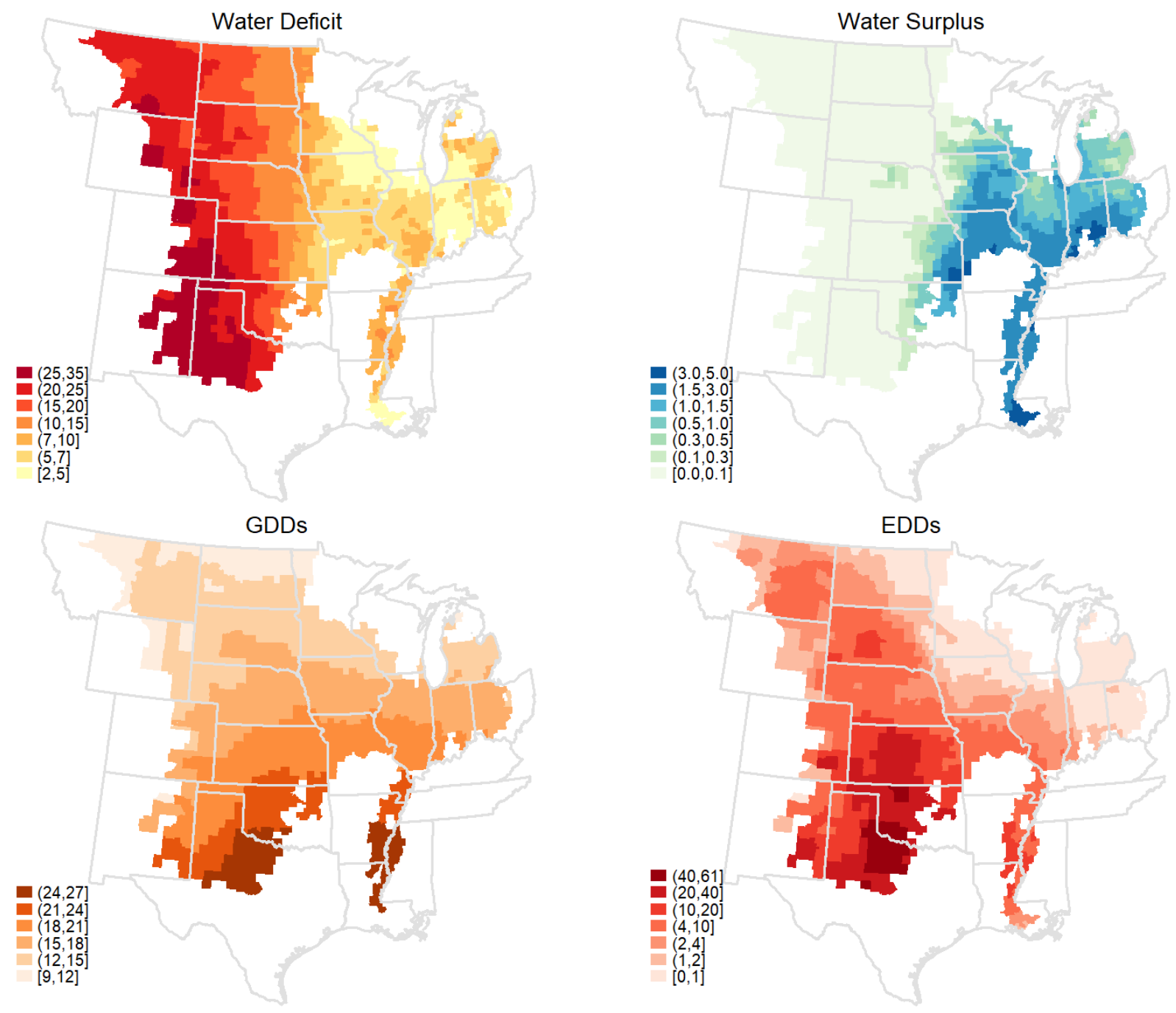

Figure 2: Spatial Distribution of Historical Climate Variables 

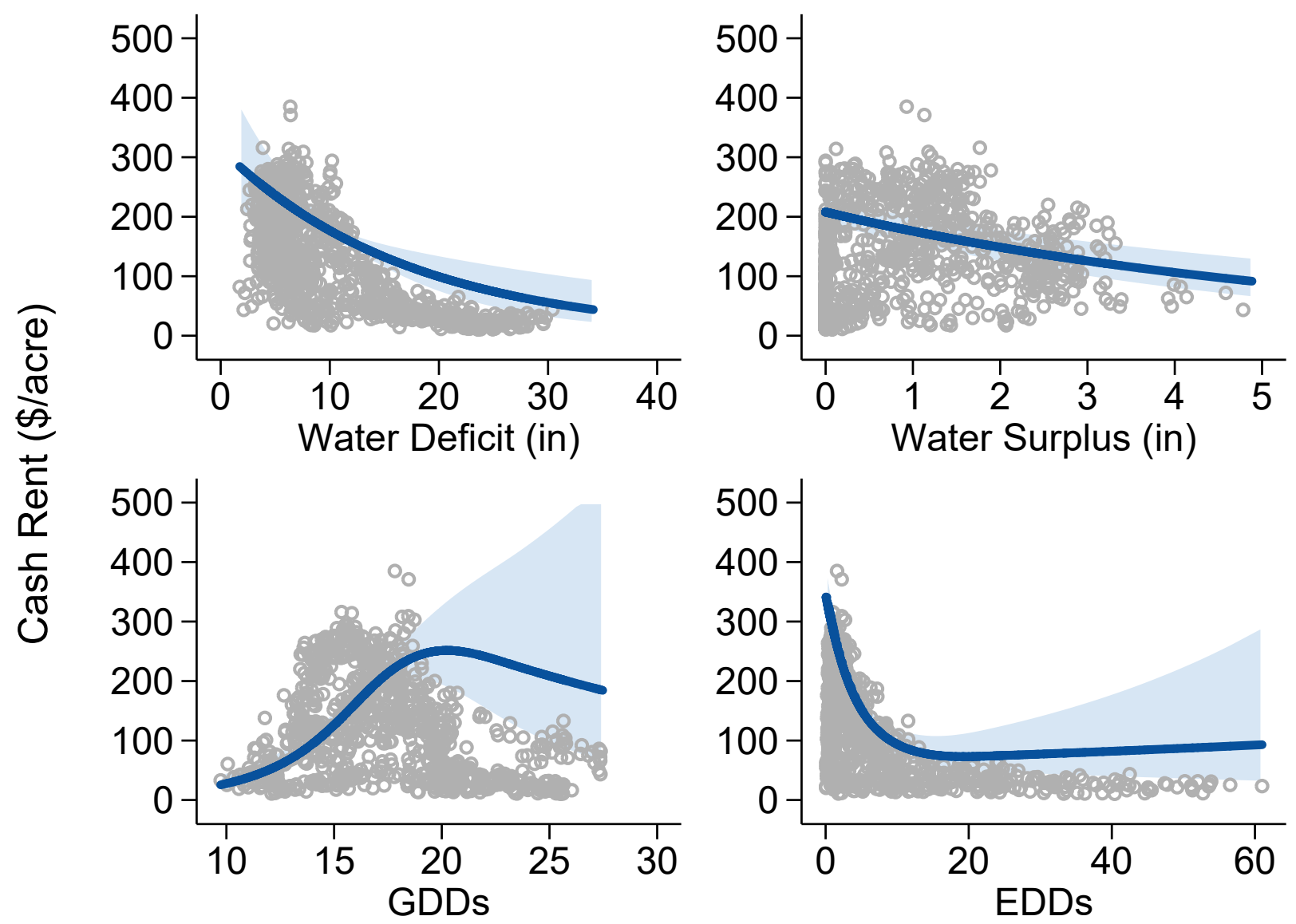

Figure 3: Predicted relationship between cash rental rates and climate variables with $95 \%$ confidence intervals. The solid lines show the predicted rental rate, the shaded areas shows the $95 \%$ confidence interval of the prediction, and the gray circles plot the observed data. 


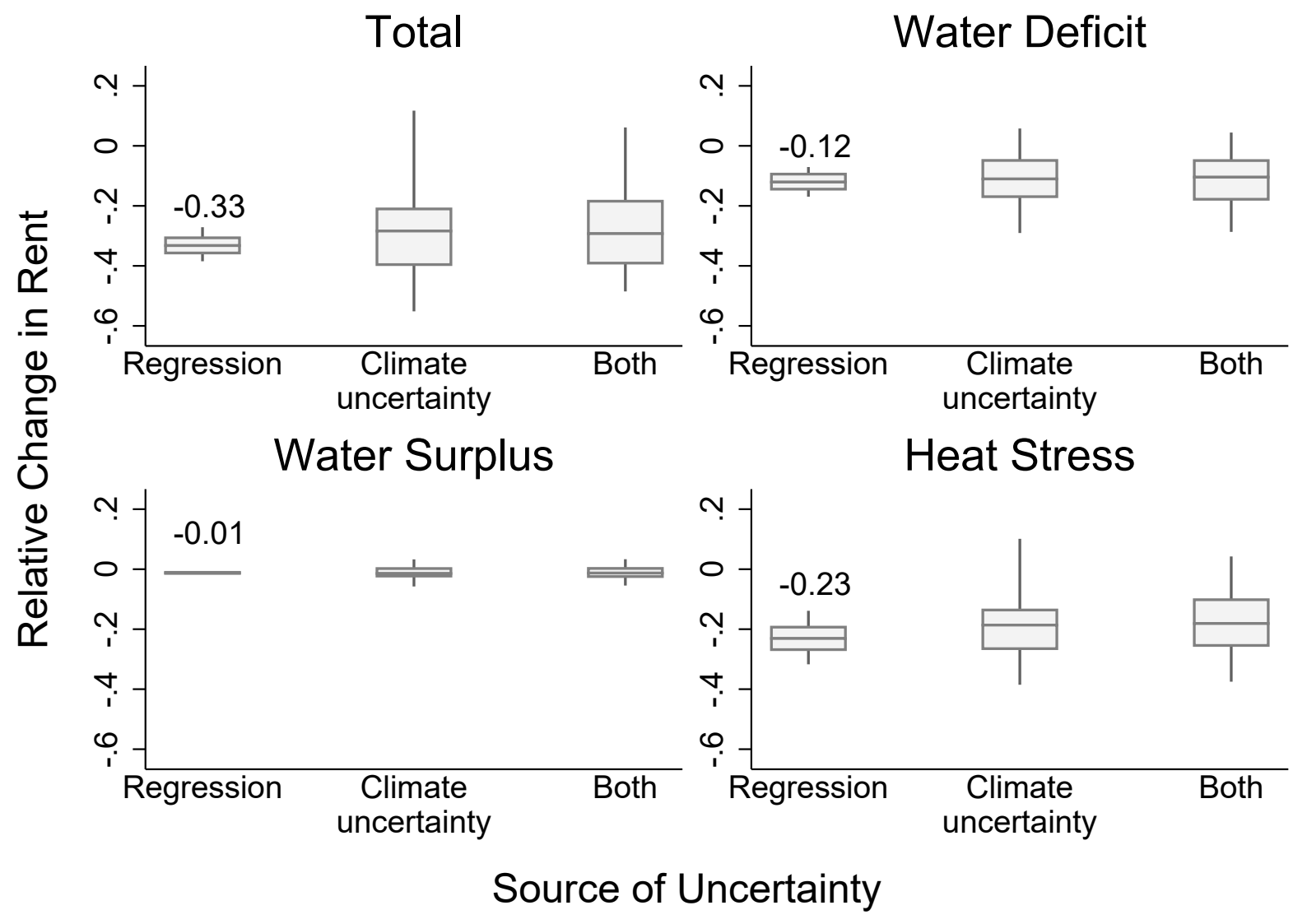

Figure 4: Median effect and uncertainty in relative change in rent due to climate change (RCP 4.5) using the projected climate at mid-century (2036-2065). The number inside each plot shows the relative change in aggregate rent due to climate change using the ensemble average change in climate variables. The top, left panel shows the overall predicted impact. The other panels show the predicted impact if only water deficit, water surplus, or heat stress were expected to change. The middle line in the box plot shows the median estimate across bootstrap replications, the upper and lower bounds of the box show the upper and lower quartiles, and the upper and lower bounds of the line show the $90 \%$ confidence interval. The three different box plots in each panel illustrate uncertainty from different sources: regression uncertainty alone, uncertainty about future climate projections, and uncertainty from the regression and climate models. 

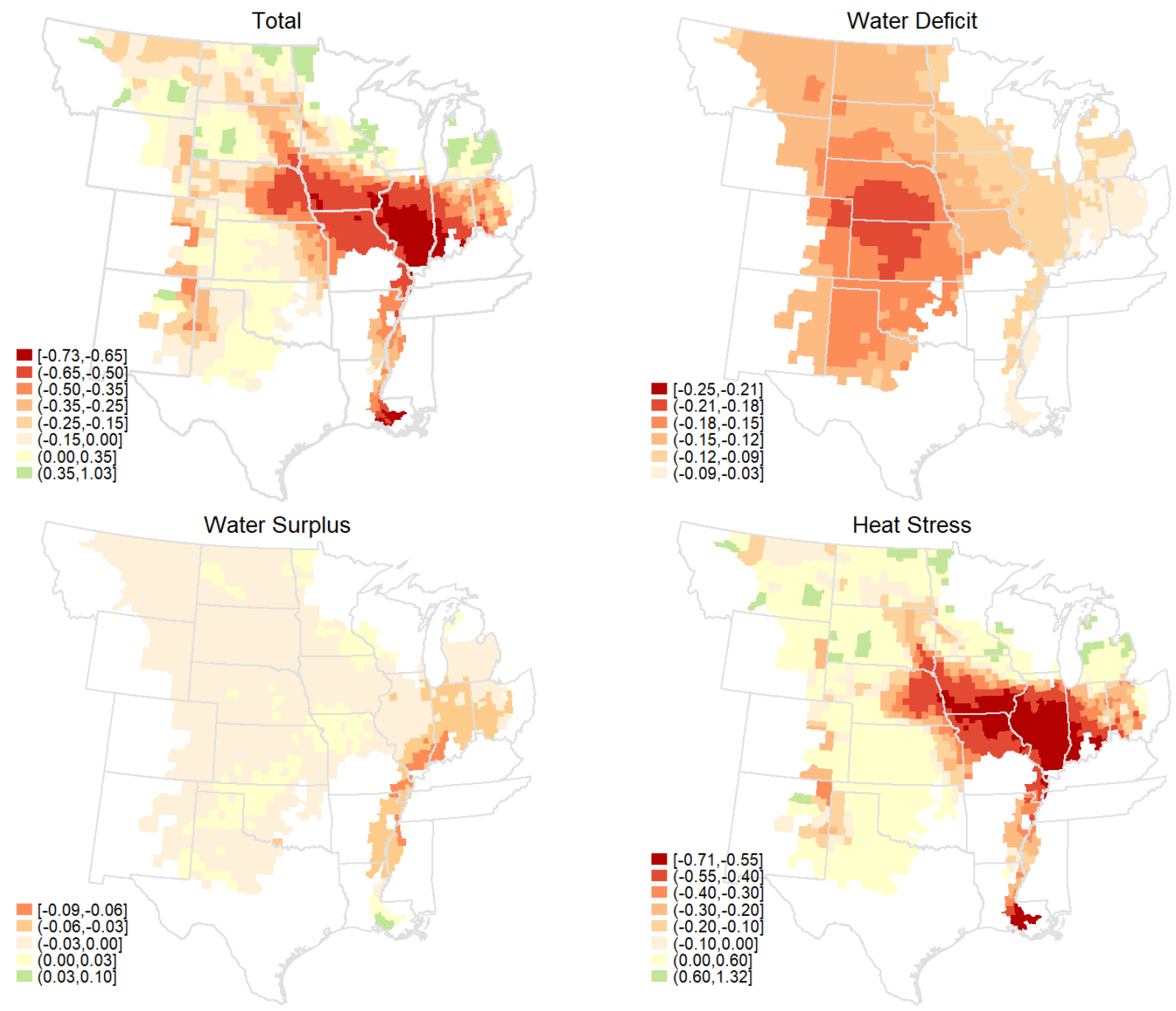

Figure 5: Spatial distribution of relative change in rent due to climate change (RCP 4.5) through each source of damages. 